\title{
PERFIL DE CONTAMINAÇÃO MICROBIOLÓGICA DE ESPECIARIAS
}

\author{
$\underline{\text { Isabel Barbosa e Barbosa }}^{1}$; Elisa Teshima ${ }^{2}$ \\ 1. Bolsista PIBIC/CNPq, Graduanda em Engenharia de Alimentos, Universidade Estadual de Feira de Santana, e-mail: \\ isabelbebarbosa@gmail.com \\ 2. Orientadora, Departamento de Tecnologia, Universidade Estadual de Feira de Santana, e-mail: eteshima@uefs.br
}

PALAVRAS-CHAVE: Especiarias, Salmonela, Bacillus ssp.

\section{INTRODUÇÃO E JUSTIFICATIVA}

Definem-se como especiarias, produtos constituídos de partes (raízes, rizomas, bulbos, cascas, folhas, flores, frutos, sementes, talos) de uma ou mais espécies vegetais, tradicionalmente utilizadas para agregar sabor ou aroma aos alimentos ou bebidas (BRASIL, 2005). As especiarias foram introduzidas no Brasil devido ao fato dessas serem utilizadas, na antiguidade, principalmente como moeda, já que tinha um alto valor comercial por servirem para conservação do alimento ou para mascarar o gosto do alimento em putrefação. No entanto, atualmente as especiarias são utilizadas pelas suas características medicinais e na culinária para conferir aroma, sabor e cor sem nenhum ganho nutricional ao alimento.

Na culinária típica da região Nordeste, verifica-se o uso frequente de especiarias como cominho (Cuminum cyminum), urucum (Bixa orellana L.), cúrcuma (Curcuma longa L. e Curcuma domestica Valenton) e pimenta do reino (Piper nigrum L.), que conferem aroma, sabor e cor à diversos pratos. Essas especiarias são comercializadas em feiras livres, na forma desidratada e na maioria das vezes, moída e a granel. A falta das boas práticas agrícolas, as precárias condições de secagem, armazenamento e de transporte tem se tornado fatores preponderantes na contaminação e proliferação de microrganismos nessas especiarias (BETTAIEB et al., 2010; PAJOHI et al., 2011).

A maioria das especiarias são utilizadas para condimentar pratos submetidos ao cozimento, que podem reduzir ou eliminar patógenos termosensíveis, no entanto, os microrganismos esporulados e termoresistentes, podem germinar e proliferar no alimento, constituindo-se um risco à saúde do consumidor. Sendo assim, o presente trabalho tem como objetivo avaliar a qualidade microbiológica de especiarias (urucum, pimenta do reino, cominho e cúrcuma) desidratadas e comercializadas a granel no mercado informal em Feira de Santana e Santo Estêvão, por meio da quantificação de microrganismos termófilos, $B$. cereus e Bacillus ssp., da pesquisa de Salmonella ssp e determinação de $\mathrm{pH}$ e Atividade de água.

\section{MATERIAL E MÉTODO}

\section{Coleta de amostras}

Foram adquiridas amostras de especiarias (urucum, pimenta do reino, cominho e cúrcuma) comercializadas a granel em feiras livres de Feira de Santana e Santo Estêvão. Foram selecionados um local de venda em Feira de Santana (FSA) e dois em Santo Estêvão (STE1 e STE2), resultando em 12 combinações de tratamentos. Em cada um dos tratamentos foram coletadas cinco amostras em ocasiões distintas, resultando na análise de 60 amostras no ano.

\section{Avaliação da qualidade microbiológica}

As amostras de especiarias foram analisadas quanto a contagem de termófilos aeróbios, Bacillus cereus, Bacillus ssp. e Salmonella ssp, de acordo com as metodologias indicadas no APHA (2001). Para as análises de termófilos aeróbios, Bacillus cereus e Bacillus $s s p$, realizou-se plaqueamento em duplicatas. Diluiu-se $25 \mathrm{~g}$ de amostra em $225 \mathrm{~mL}$ de água 
peptonada $\left(10^{-1}\right)$ e, para as diluições decimais seguintes, adicionou-se $1 \mathrm{~mL}$ da diluição anterior a $9 \mathrm{~mL}$ de água peptonada.

Para análise de Bacillus cereus e Bacillus ssp., fez-se o plaqueamento por superfície nas diluições $10^{-1}$ a $10^{-3}$ no meio Agar Manitol Gema de Ovo Polimixina (MYP), incubandoas a $48 \mathrm{~h} / 35^{\circ} \mathrm{C}$. A contagem dos microrganismos termófilos foi realizada pelo plaqueamento em profundidade nas diluições $10^{-2}$ a $10^{-4}$ no meio Agar Plate Count Agar (PCA), incubou-as por $48 \mathrm{~h} / 55^{\circ} \mathrm{C}$.

A pesquisa de Salmonella ssp. consistiu de: pré-enriquecimento (diluiu-se $25 \mathrm{~g}$ de amostra em $225 \mathrm{~mL}$ de caldo lactosado, incubando-o por $20 \mathrm{~h} / 35^{\circ} \mathrm{C}$ ), enriquecimento seletivo no caldo tetrationato e Rappaport Vassiliadis, isolamento e seleção nos Agar Verde Brilhante, Agar Desoxicolato-Lisina-Xilose e Agar Hektoen Enteric, e testes bioquímicos em Agar Triplo Açúcar Ferro e Agar Lisina de Ferro, seguidos de teste de hidrólise de uréia.

\section{Avaliação físico-química}

As amostras de especiarias foram analisadas quanto a Atividade de água e $\mathrm{pH}$, de acordo com a metodologia descrita no manual de análise físico-química de alimentos do INSTITUTO ADOLFO LUTZ (1985).

\section{ANÁLISE E DISCUSSÃO DOS RESULTADOS}

Os resultados de contaminação por B. cereus, Bacillus ssp, microrganismos termófilos nas amostras de cominho, pimenta do reino, urucum e cúrcuma de feiras livres de Feira de Santana e Santo Estêvão estão apresentados na Tabela 1.

Tabela 1. Nível de contaminação microbiológica de especiarias comercializadas em Feira de Santana (FSA) e Santo Estêvão (STE1 e STE2).

\begin{tabular}{|c|c|c|c|c|c|}
\hline Microrganismos & Local & $\begin{array}{c}\text { Cominho } \\
\text { (Log } \\
\text { UFC/g) }\end{array}$ & $\begin{array}{l}\text { Pimenta do } \\
\text { Reino } \\
\text { (Log UFC/g) }\end{array}$ & $\begin{array}{c}\text { Urucum } \\
\text { (Log } \\
\text { UFC/g) }\end{array}$ & $\begin{array}{c}\text { Cúrcuma } \\
\text { (Log } \\
\text { UFC/g) }\end{array}$ \\
\hline \multirow{3}{*}{ B. cereus } & FSA & $4,18 \pm 0,90^{\mathrm{a}}$ & $4,73 \pm 1,31^{\mathrm{a}}$ & $1,94 \pm 2,09^{a}$ & $4,77 \pm 1,11^{\mathrm{a}}$ \\
\hline & STE1 & $4,04 \pm 2,30^{\mathrm{a}}$ & $4,06 \pm 2,32^{\mathrm{a}}$ & $3,12 \pm 2,15^{\mathrm{a}}$ & $3,80 \pm 1,79^{\mathrm{a}}$ \\
\hline & STE2 & $3,79 \pm 2,04^{\mathrm{a}}$ & $3,86 \pm 2,13^{\mathrm{a}}$ & $3,37 \pm 1,53^{\mathrm{a}}$ & $3,86 \pm 1,90^{\mathrm{a}}$ \\
\hline \multicolumn{2}{|l|}{$\% \mathrm{CV}$} & 44,48 & 44,67 & 69,32 & 39,59 \\
\hline \multirow{3}{*}{ Bacillus ssp. } & FSA & $3,71 \pm 1,68^{\mathrm{a}}$ & $4,76 \pm 0,53^{\mathrm{a}}$ & $2,80 \pm 1,84^{\mathrm{a}}$ & $2,38 \pm 1,99^{\mathrm{a}}$ \\
\hline & STE1 & $4,31 \pm 2,09^{\mathrm{a}}$ & $5,46 \pm 1,36^{\mathrm{a}}$ & $3,94 \pm 2,48^{\mathrm{a}}$ & $3,46 \pm 2,53^{\mathrm{a}}$ \\
\hline & STE2 & $3,82 \pm 1,94^{\mathrm{a}}$ & $4,52 \pm 2,16^{\mathrm{a}}$ & $2,57 \pm 1,50^{\mathrm{a}}$ & $3,65 \pm 1,67^{\mathrm{a}}$ \\
\hline \multicolumn{2}{|l|}{$\% \mathrm{CV}$} & 48,42 & 30,70 & 63,84 & 66,19 \\
\hline \multirow{3}{*}{$\begin{array}{c}\text { Termófilos } \\
\text { Aeróbios }\end{array}$} & FSA & $4,80 \pm 0,33^{\mathrm{a}}$ & $5,39 \pm 0,98^{\mathrm{a}}$ & $3,47 \pm 1,50^{\mathrm{a}}$ & $5,52 \pm 0,29^{\mathrm{a}}$ \\
\hline & STE1 & $5,33 \pm 0,43^{b}$ & $5,38 \pm 0,78^{\mathrm{a}}$ & $4,21 \pm 0,79^{\mathrm{a}}$ & $5,16 \pm 0,77^{\mathrm{a}}$ \\
\hline & STE2 & $5,33 \pm 0,32^{b}$ & $5,06 \pm 0,90^{\mathrm{a}}$ & $4,05 \pm 0,52^{\mathrm{a}}$ & $4,83 \pm 0,57^{\mathrm{a}}$ \\
\hline \multicolumn{2}{|l|}{$\% \mathrm{CV}$} & 7,00 & 16,91 & 26,19 & 11,20 \\
\hline
\end{tabular}

Médias seguidas por letras iguais na mesma coluna não diferem significativamente entre si $(\mathrm{p}<0,05)$.

Franco (2002) afirma o consumo de alimentos com número de células viáveis de $B$. cereus entre $10^{7}$ e $10^{9}$ levam a manifestação da síndrome diarréica e síndrome emética, provenientes da toxina diarréica e emética. Os valores médios das contaminações por este microrganimo nas amostras analisadas estão abaixo deste valor, no entanto os resultados de algumas amostras indicativas da pimenta do reino apresentaram níveis superiores a $10^{7}$, sendo estas impróprias ao consumo humano.

As especiarias em geral são submetidas ao processo de secagem solar ou em secadores em torno de $60^{\circ} \mathrm{C}$, temperatura ótima para o crescimento destes microrganismos, mas não é 
suficiente para destruir esses microrganismos. A maioria das bactérias termófilas aeróbicas importantes em alimentos pertence aos gêneros de Bacillus incluindo as espécies deteriorantes como Bacillus coagulans, Bacillus subtilis e Bacillus stearothermophillus (FRANCO, 2002). Verificou-se que os níveis de Bacillus ssp. no local STE1 ocorreu em maior quantidade nas amostras de cominho, pimenta do reino e urucum. Para a cúrcuma, STE2 apresentou maior contaminação.

Com relação às bactérias termófilas observou-se a maior quantidade no cominho tanto nos locais STE1 e STE2. Para a pimenta do reino, FSA e STE1 apresentaram maior contaminação com resultados próximos. No urucum e na cúrcuma foram detectados elevadas contaminações em STE1 e FSA, respectivamente. Segundo Carvalho (2010), a contagem de bactérias termófilas é indicativa de deterioração do alimento submetido a tratamento térmico.

A presença de salmonela verificada nas amostras de cominho, pimenta do reino, urucum e cúrcuma comercializadas em Feira de Santana e Santo Estêvão estão apresentadas no Gráfico 1.
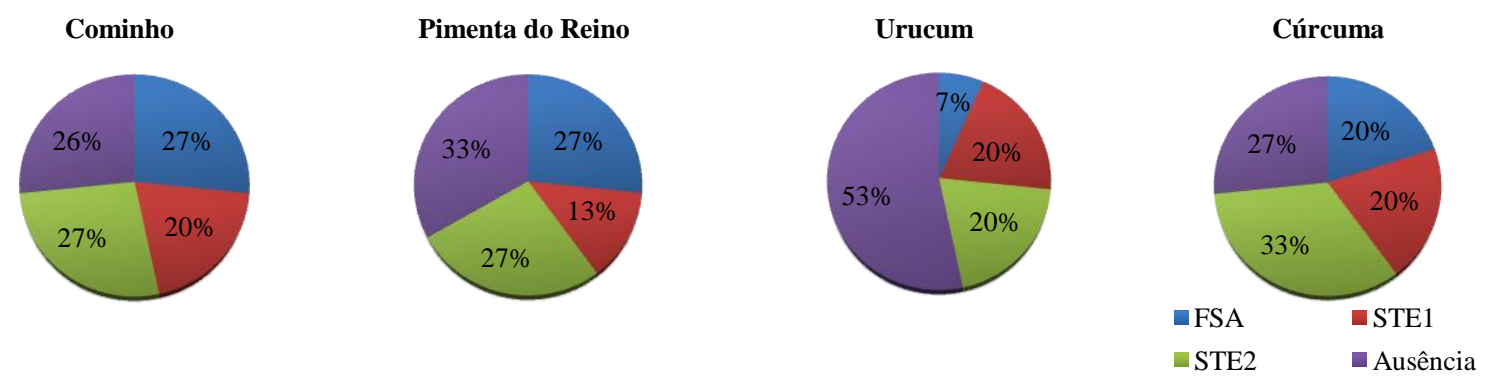

Gráfico 1. Contaminação de Salmonela em especiarias comercializadas em Feira de Santana (FSA) e Santo Estêvão (STE1 e STE2).

Segundo a RDC 12/2001 da ANVISA (BRASIL, 2001), as especiarias devem apresentar ausência de Salmonella sp.. Verificou-se que 74\% das amostras de cominho, $67 \%$ das amostras de pimenta do reino, $73 \%$ das amostras de cúrcuma e $47 \%$ das amostras de urucum apresentaram presença de Salmonela, sendo estas improprías para comercialização e consumo, por apresentarem risco à saúde.

Os fatores intrínsecos $\mathrm{pH}$ e Aw estão diretamente relacionados ao crescimento microbiano e atuando em conjunto, garantem condições ótimas para a proliferação de microorganismos deteriorantes e patogênicos. Os valores obtidos de $\mathrm{pH}$ e $\mathrm{Aw}$ das especiarias estão apresentadas na Tabela 2.

Tabela 2. Valores de pH e Atividade de água das especiarias comercializadas em Feira de Santana (FSA) e Santo Estêvão (STE1 e STE2).

\begin{tabular}{|c|c|c|c|c|c|}
\hline Parâmetros & Local & Cominho & Pimenta do Reino & Urucum & Cúrcuma \\
\hline \multirow{3}{*}{$\mathbf{p H}$} & FSA & $5,46 \pm 0,05^{b}$ & $6,39 \pm 0,25^{\mathrm{a}}$ & $6,15 \pm 0,29^{a}$ & $6,65 \pm 0,17^{\mathrm{a}}$ \\
\hline & STE1 & $5,66 \pm 0,11^{b}$ & $5,98 \pm 0,31^{\mathrm{a}}$ & $6,16 \pm 0,22^{\mathrm{a}}$ & $6,05 \pm 0,35^{b}$ \\
\hline & STE2 & $5,73 \pm 0,11^{\mathrm{a}}$ & $6,02 \pm 0,29^{\mathrm{a}}$ & $6,18 \pm 0,08^{\mathrm{a}}$ & $6,27 \pm 0,13^{b}$ \\
\hline \multicolumn{2}{|c|}{$\% \mathrm{CV}$} & 1,66 & 4,72 & $\mathbf{3 , 5 0}$ & 3,75 \\
\hline \multirow{3}{*}{ Aw } & FSA & $0,545 \pm 0,070^{a}$ & $0,536 \pm 0,060^{\mathrm{a}}$ & $0,521 \pm 0,240^{\mathrm{a}}$ & $0,519 \pm 0,060^{\mathrm{a}}$ \\
\hline & STE1 & $0,534 \pm 0,020^{a}$ & $0,532 \pm 0,020^{\mathrm{a}}$ & $0,519 \pm 0,020^{\mathrm{a}}$ & $0,523 \pm 0,020^{\mathrm{a}}$ \\
\hline & STE2 & $0,525 \pm 0,030^{a}$ & $0,533 \pm 0,020^{\mathrm{a}}$ & $0,522 \pm 0,030^{\mathrm{a}}$ & $0,500 \pm 0,020^{\mathrm{a}}$ \\
\hline \multicolumn{2}{|c|}{$\% \mathrm{CV}$} & 8,85 & 6,76 & 8,03 & 7,41 \\
\hline
\end{tabular}

Médias seguidas por letras iguais na mesma coluna não diferem significativamente entre si $(\mathrm{p}<0,05)$. 
De acordo com Jay (2005), o crescimento ótimo da Samonella requer pH entre 6,6 e 8,2. De acordo com Franco (2002), a faixa de pH em que ocorre a multiplicação de $B$. cereus varia de 4,9 a 9,3; e a Aw mínima necessária para o crescimento é 0,95. Pode-se observar que a faixa de $\mathrm{pH}$ encontrada nas especiarias analisadas está próxima da faixa ótima para proliferação dos patógenos e que mesmo apresentando Aw abaixo do mínimo estabelecido para crescimento de B. cereus, houve presença da bactéria em todas as amostras. Pelos resultados obtidos, verificou-se que os valores de $\mathrm{pH}$ das amostras de cominho e cúrcuma de Feira de Santana foram menores e maiores $(\mathrm{P}<0,05)$, respectivamente, que as amostras de Santo Estêvão.

\section{CONCLUSÃO}

As especiarias comercializadas em feiras livres de Feira de Santana e Santo Estêvão apresentam contaminação elevada de microrganismos deteriorantes e patogênicos. Verificouse que $74 \%$ das amostras de cominho, $67 \%$ das amostras de pimenta do reino, $73 \%$ das amostras de cúrcuma e $47 \%$ das amostras de urucum apresentaram presença de Salmonela, sendo estas improprías para comercialização e consumo, por apresentarem risco à saúde.

As contaminações das especiarias, obtidas em ocasiões distintas (possivelmente de lotes diferentes), apresentaram uma elevada variação da quantidade de contaminação entre amostras de cada especiaria no mesmo local de comercialização, indicando a falta de padrão de qualidade das especiarias comercializadas a granel em feiras livres de Feira de Santana e Santo Estêvão.

\section{REFERÊNCIAS}

APHA. 2001. American Public Health Association. Compendium of Methods for the Microbiological Examination of Foods. 4th ed., Washington, 676p..

BETTAIEB, I., BOURGOU, S., WANNES, W. A., HAMROUNI,I., LiMAM, F., MARZOUK B. 2010.Essential Oils Phenolics and Antioxidant Activities of Different Parts of Cumin (Cuminum cyminum L.), Journal of Agricultural and Food Chemistry, 58, p 1041010418.

BRASIL. 2005.Ministério da Agricultura e Abastecimento. RDC n ${ }^{\circ}$ 276, de 22 de setembro de 2005. "Regulamento técnico para especiarias, temperos e molhos". Diário Oficial da União; Poder Executivo, de 23 de setembro de 2005.

BRASIL. 2001. Ministério da Saúde. Agência Nacional de Vigilância Sanitária. Resolução $\mathrm{n}^{\circ} 12$ de 10 de janeiro de 2001. Regulamento técnico sobre padrões microbiológicos para alimentos. Diário Oficial da União; Poder Executivo, de 11 de janeiro de 2001.

CARVALHO, I. T. 2010. Microbiologia dos Alimentos. Programa Escola Técnica Aberta do Brasil (ETEC). Recife: EDUFRPE. Disponível em:< http://redeetec.mec.gov.br/images/stories/pdf/eixo_prod_alim/tec_alim/181012_micro_alim.p df>. Acesso em: 06 de Jul. de 2017.

FRANCO, B. D. G. M.; LADGRAF, M. 2002. Microbiologia dos alimentos. São Paulo, SP: Atheneu, 181p.

INSTITUTO ADOLFO LUTZ. 1985. Normas analíticas, métodos químicos e físicos para análise de alimentos. São Paulo, 533 p.

JAY, J. M. 2005. Microbiologia de alimentos. 6 ed. Porto Alegre: Artmed, 711 p.

PAJOHI, M.R., TAJIK, H., FARSHID, A.A, HADIAN, M. 2011. Synergistic antibacterial activity of the essential oil of Cuminum cyminum L. seed and nisin in a food model, Journal of Applied Microbiology, 110, p 943-951, ISSN 1364-5072. 